\title{
Stepwise enhancement of catalytic performance of haloalkane dehalogenase LinB towards $\beta$-hexachlorocyclohexane
}

\author{
Ryota Moriuchi ${ }^{1,3}$, Hiroki Tanaka ${ }^{1}$, Yuki Nikawadori ${ }^{1}$, Mayuko Ishitsuka ${ }^{1}$, Michihiro Ito ${ }^{1,4}$, Yoshiyuki Ohtsubo ${ }^{1}$, \\ Masataka Tsuda', Jiri Damborsky², Zbynek Prokop ${ }^{2}$ and Yuji Nagata ${ }^{1{ }^{*}}$
}

\begin{abstract}
Two haloalkane dehalogenases, LinBut and LinB $\mathrm{MI}_{\text {, }}$ each with 296 amino acid residues, exhibit only seven amino acid residue differences between them, but $\mathrm{LinB}_{\mathrm{MI}}$ 's catalytic performance towards $\beta$-hexachlorocyclohexane $(\beta-\mathrm{HCH})$ is considerably higher than LinBuT's. To elucidate the molecular basis governing this difference, intermediate mutants between LinB $B_{U T}$ and LinB $B_{M I}$ were constructed and kinetically characterized. The activities of LinB $B_{U T}$-based mutants gradually increased by cumulative mutations into LinB $\mathrm{BT}_{\text {, }}$ and the effects of the individual amino acid substitutions depended on combination with other mutations. These results indicated that LinBuT's $\beta$-HCH degradation activity can be enhanced in a stepwise manner by the accumulation of point mutations.
\end{abstract}

Keywords: $\beta$-Hexachlorocyclohexane; Xenobiotics; Biodegradation; Haloalkane dehalogenase; Protein evolution

\section{Introduction}

$\gamma$-Hexachlorocyclohexane $(\gamma-\mathrm{HCH}$; also known as $\gamma$ - $\mathrm{BHC}$ or lindane) is a manmade and xenobiotic halogenated insecticide that was once used worldwide on a large scale. A number of soil bacterial strains that can aerobically degrade $\gamma-\mathrm{HCH}$ have been isolated from geographically distant locations (Lal et al. 2010; Ito et al. 2007; Lal et al. 2006; Mohn et al. 2006; Phillips et al. 2005). As this novel compound was first released into the environment in the 1940s, they must have evolved quickly to utilize it.

An industrial chemical process of benzene photochlorination generates so-called technical- $\mathrm{HCH}(\mathrm{t}-\mathrm{HCH})$, which consists mainly of five isomers, $\alpha-(60-70 \%), \gamma-(12-$ $16 \%), \beta-(10-12 \%), \delta-(6-10 \%)$, and $\varepsilon-\mathrm{HCH}(3-4 \%)$ (Vijgen et al. 2011). Among these isomers, only $\gamma-\mathrm{HCH}$ has insecticidal activity; this isomer was therefore purified. The remaining isomers were in many cases improperly deposited, causing serious environmental problems. $\alpha$ - and $\beta-\mathrm{HCH}$ isomers as well as $\gamma-\mathrm{HCH}$ were categorized as persistent organic pollutants (POPs) at the Stockholm Convention (Vijgen et al. 2011). Among the $\mathrm{HCH}$ isomers,

\footnotetext{
* Correspondence: aynaga@ige.tohoku.ac.jp

'Department of Environmental Life Sciences, Graduate School of Life

Sciences, Tohoku University, Sendai 980-8577, Japan

Full list of author information is available at the end of the article
}

$\beta-\mathrm{HCH}$ is the most recalcitrant; it is usually the predominant isomer remaining in contaminated soils and in animal tissues and fluids (Willett, et al. 1998). All six chlorines of $\beta-\mathrm{HCH}$ in equatorial positions seem to contribute to its having the greatest chemical stability among the isomers. Several $\beta$ - $\mathrm{HCH}$-degrading bacterial strains have also been identified (Johri et al. 1998; Gupta et al. 2000, 2001). Haloalkane dehalogenase (HLD) LinB, which was originally described as an enzyme involved in $\gamma$-HCH degradation in Sphingobium japonicum UT26 (LinB $\mathrm{UT}_{\mathrm{UT}}$ ) (Nagata et al. 1993), was more recently identified as an enzyme possessing $\beta-\mathrm{HCH}$ degradation activity (Nagata et al. 2005; Sharma et al. 2006) (Figure 1).

HLDs belong to the $\alpha / \beta$-hydrolase family, and their catalytic mechanism consists of the following steps: substrate binding, cleavage of the carbon-halogen bond in the substrate and simultaneous formation of an intermediate covalently bound to a nucleophile, hydrolysis of the alkylenzyme intermediate, and release of halide ion and alcohol (Damborsky and Koca 1999; Janssen 2004; Prokop et al. 2003). LinB $\mathrm{BI}_{\mathrm{MI}}$ isolated from Sphingobium sp. MI1205 (Ito et al. 2007) and $\mathrm{LinB}_{\mathrm{UT}}$ each consist of 296 amino acid residues and share $98 \%$ sequence identity, with only seven different amino acid residues between them, at the positions 81, 112, 134, 135, 138, 247, and 253 (Figure 2).

\section{Springer}




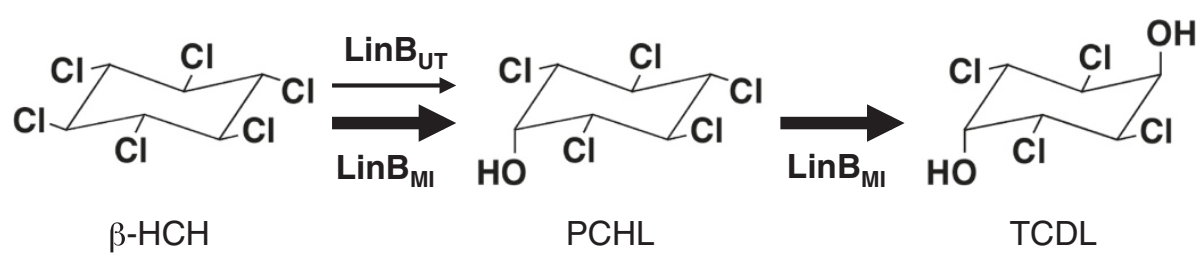

Figure $1 \beta-H C H$ degradation reactions catalyzed by $\operatorname{LinB}_{U T}$ and $\operatorname{LinB}_{M !}$. LinB $B_{M l}$ converts $\beta-H C H$ to $P C H L$ and further to TCDL, while LinB $B_{U T}$ catalyzes only the first conversion step of $\beta-\mathrm{HCH}$ to PCHL.

However, these two enzymes exhibit significantly different enzymatic behaviors in $\beta-\mathrm{HCH}$ degradation (Figure 1). $\operatorname{LinB}_{\mathrm{MI}}$ catalyzes the two-step dehalogenation and converts $\beta-\mathrm{HCH}$ to 2,3,4,5,6-pentachlorocyclohexanol (PCHL) and then to 2,3,5,6-tetrachlorocyclohexane-1,4-diol (TCDL) ( LinB $_{\mathrm{MI}^{-}}$-type activity) (Ito et al. 2007), whereas $\operatorname{LinB}_{\mathrm{UT}}$ catalyzes only the former step (Nagata et al. 2005) (Figure 1). Furthermore, $\operatorname{LinB}_{\mathrm{MI}}$ can catalyze the first conversion step an order of magnitude more rapidly than $\operatorname{Lin}_{U \mathrm{UT}}$ (Ito et al. 2007). Substitution of the $\operatorname{Lin}_{\mathrm{UT}}$
I134 and A247 residues, which form the catalytic pocket, to the LinB $\mathrm{BI}_{\mathrm{MI}}$-type $\mathrm{V}$ and $\mathrm{H}$ residues, respectively, resulted in only a weak effect on $\mathrm{LinB}_{\mathrm{MI}}$-type activity (Ito et al. 2007). Additionally, the reciprocal double mutant of $\operatorname{LinB}_{\mathrm{MI}}$ (V134I/H247A) still retained relatively high $\operatorname{Lin}_{\mathrm{MI}}$-type activity (Ito et al. 2007). These results indicated that one or more of the five other residues are also important for LinB $\mathrm{MI}_{\mathrm{MI}}$-type activity. Our previous sitedirected mutagenesis and X-ray crystallographic studies of $\operatorname{LinB}_{\mathrm{MI}}$ (Okai et al. 2013) indicated that (i) these five

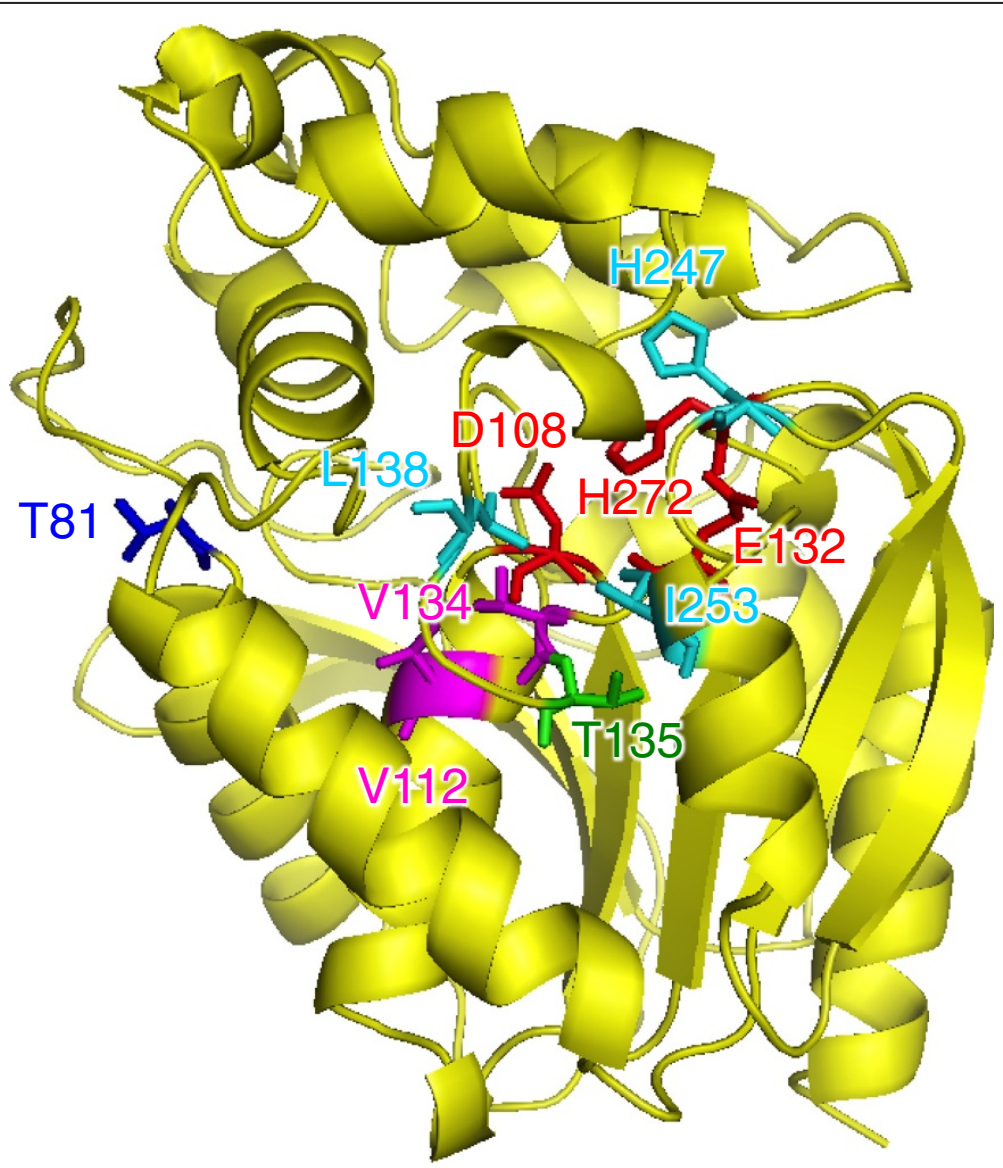

Figure 2 Structure of $\mathrm{LinB}_{\mathrm{MI}}$ (PDB code 4H77) (Okai et al. 2013) and location of catalytic triad (D108, E132, and H272; shown in red) and the seven dissimilar amino acid residues between $\operatorname{LinB}_{M I}$ and LinB $\mathrm{UT}_{\mathrm{U}}$ : V134 and V112 (in magenta), L138, H247, and I253 (in cyan), T135 (in green), and T81 (in blue). See text for detail. 
residues are not essential to the $\mathrm{LinB}_{\mathrm{MI}}$-type activity, but they all significantly contribute to this activity, and (ii) three of the five residues, V112, L138, and I253, are more important than $\mathrm{T} 81$ and $\mathrm{T} 135$ for the conversion of PCHL. The structural basis for the importance of the seven amino acid residues of $\operatorname{LinB}_{\mathrm{MI}}$ can be partially explained by analysis of its tertiary structure (Figure 2). V134 and V112 are located at the catalytic pocket near the nucleophile residue (D108) and at the bottom of the substrate binding pocket, respectively, while L138, H247, and I253 are located at the access tunnels to the catalytic pocket. Therefore, these five amino acid residues may be directly involved in LinB $\mathrm{MI}_{\mathrm{MI}}$-type activity (Okai et al. 2013). The effect of T135 on LinB $_{\mathrm{MI}}$-type activity may be due to its interaction with I253. However, it is unclear how T81, which is located at the protein surface and far from the active site, affect the activity.

In this study, cumulative mutations were introduced into $\mathrm{LinB}_{\mathrm{UT}}$, and the resulting intermediate mutant enzymes between $\operatorname{LinB}_{\mathrm{UT}}$ and $\operatorname{Lin}_{\mathrm{MI}}$ were characterized in order to gain more insight into the molecular evolution of LinB towards $\beta-\mathrm{HCH}$ degradation activity. Since the

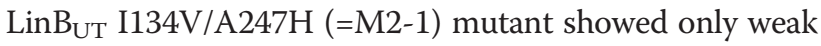
$\mathrm{LinB}_{\mathrm{MI}}$-type activity in our previous study (Ito et al. 2007), cumulative mutations at the positions A112, I138, and M253 were introduced into the M2-1 mutant. On the basis of kinetic analyses of the resulting three-, four-, and five-point LinB $B_{U T}$ mutants (Figures 3, 4 and Table 1), enhancement of the catalytic performance of $\operatorname{LinB}_{U T}$ towards $\beta-\mathrm{HCH}$ is discussed.

\section{Materials and methods}

\section{Expression and purification of enzymes}

The nomenclature of LinB mutants used in this study is shown in Table 1. An established method was used for site-directed mutagenesis (Ito et al. 2007). The expression plasmids for the 10 LinB $_{\mathrm{UT}}$ multiple mutants, M3-1 (A112V/I134V/A247H), M3-2 (I134V/I138L/A247H), M3-3 (I134V/A247H/M253I), M4-1 (A112V/I134V/I138L/A247H), M4-2 (I134V/I138L/A247H/M253I), M5-1 (A112V/I134V/ I138L/A247H/M253I), M5-2 (A81T/I134V/I138L/A247H/ M253I), M5-3 (I134V/A135T/I138L/A247H/M253I), M5-4 (A81T/A112V/I134V/I138L/A247H), and M5-5 (A112V/ I134V/A135T/I138L/A247H), were constructed as described previously using the vector pAQNM (Ito et al. 2007). The His-tagged target proteins were expressed under the control of the tac promoter and lacl ${ }^{\mathrm{q}}$. E. coli BL21 Star (DE3) cells expressing $\operatorname{Lin}_{\mathrm{UT}}$ mutants were disrupted by bacteriolysis using a CelLytic B Reagent (Sigma), and His-tagged enzymes were purified by using BD TALON Metal Affinity Resins (BD Biosciences). Only one protein band corresponding to about $33 \mathrm{kDa}$ was observed on sodium dodecyl sulfate (SDS)-polyacrylamide gel electrophoresis after the purification (data not shown).

\section{Enzymatic assays}

The purified enzyme was incubated with $17 \mu \mathrm{M}$ of $\beta$ $\mathrm{HCH}$ in $50 \mathrm{mM}$ potassium phosphate buffer $(\mathrm{pH} 7.5)$ containing $10 \%(\mathrm{v} / \mathrm{v})$ glycerol at $30^{\circ} \mathrm{C}$. The enzyme concentration in the reaction mixture was $150 \mu \mathrm{g} / \mathrm{ml}$. The mixture $(100 \mu \mathrm{l})$ was extracted with an equal volume of ethyl acetate and then analyzed by a Shimadzu GC-17A gas chromatograph equipped with a ${ }^{63} \mathrm{Ni}$ electron capture detector (ECD) and Rtx-1 capillary column (30 m $\times 0.25$ $\mathrm{mm} \times 0.25 \mu \mathrm{m}$; Restek). The column temperature was increased from $160^{\circ} \mathrm{C}$ to $200^{\circ} \mathrm{C}$ at a rate of $4^{\circ} \mathrm{C} / \mathrm{min}$, and then from $200^{\circ} \mathrm{C}$ to $260^{\circ} \mathrm{C}$ at a rate of $20^{\circ} \mathrm{C} / \mathrm{min}$. The gas flow rate was a constant $30 \mathrm{ml} / \mathrm{min}$. As the internal standard, $10 \mu \mathrm{M}$ 2,4,5-trichlorophenol was used. Due to the low solubility of $\beta-\mathrm{HCH}$ in water, the $k_{\text {cat }}$ and $K_{\mathrm{m}}$ values of the mutants could not be calculated. Kinetic data were fitted to the irreversible two-step reaction scheme of $\beta-\mathrm{HCH}$ conversion to TCDL via PCHL (Scheme 1). Nonlinear regression provided estimates of the specificity constants and standard errors for both reaction steps $\left(k_{1}\right.$ and $\left.k_{2}\right)$ by using GEPASI 3.2 software (Mendes 1997).

$$
\begin{gathered}
\mathrm{E}+\mathrm{HCH} \stackrel{k 1}{\rightarrow} \mathrm{E}+\mathrm{PCHL} \stackrel{k 2}{\rightarrow} \mathrm{E}+\mathrm{TCDL} \\
\text { Scheme } 1
\end{gathered}
$$

\section{Results \\ Characterization of single- and double-point mutants of $\operatorname{LinB}_{U T}$}

Since M2-1 showed only a weak $\operatorname{LinB}_{\mathrm{MI}}$-type activity in the previous study (Ito et al. 2007), we introduced further mutations into M2-1 in this study. However, for the critical comparison with other mutants, the seven single-point mutants [A81T (M1-1), A112V (M1-2), I134V (M1-3), A135T (M1-4), I138L (M1-5), A247H (M1-6), and M253I (M1-7)] of LinB ${ }_{\mathrm{UT}}$ and M2-1 were also kinetically characterized in this study, and the importance of individual mutations for Lin $\mathrm{B}_{\mathrm{MI}}$ activity towards $\beta-\mathrm{HCH}$ was assessed (Figure 3 and Table 1). Among the seven single-point mutations, only the A112V mutation had a negative effect on $\beta-\mathrm{HCH}$ degradation activity, while the other six mutations showed a slightly positive effect on enzymatic activity towards $\beta-\mathrm{HCH}$ (Figure $3 \mathrm{~b}-\mathrm{h}$ and Figure 5). Interestingly, the A81T mutation had a relatively strong effect on the first conversion $(\beta-\mathrm{HCH}$ to PCHL) step (Figure $3 \mathrm{~b}$ and Figure $5 \mathrm{e})$. The involvement of T81 in the first step was consistent with the decrease in this step by the reciprocal T81A mutation into $\operatorname{LinB}_{\mathrm{MI}}$ (M6-1) (Figure 5e and Additional file 1: Figure S1b) (Okai et al. 2013). M2-1 showed higher activity for the second conversion (PCHL to TCDL) step (Table 1) than all the single mutants, but its activity was still weak (Figure $3 i$ and Figure 5a). 


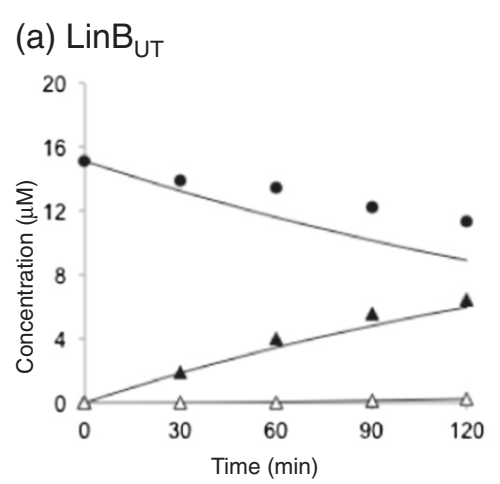

(b) $\mathrm{M} 1-1\left(\operatorname{LinB}_{\mathrm{UT}} \mathrm{A} 81 \mathrm{~T}\right)$

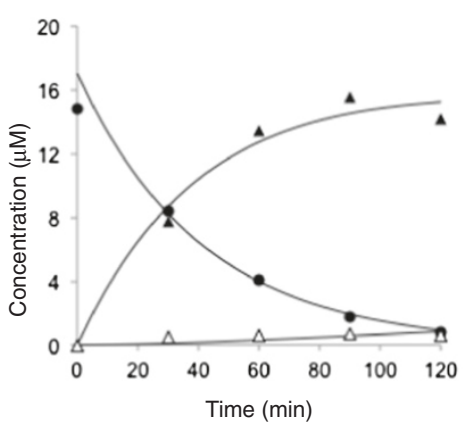

(d) M1-3 ( LinB $_{U T}$ I134V)

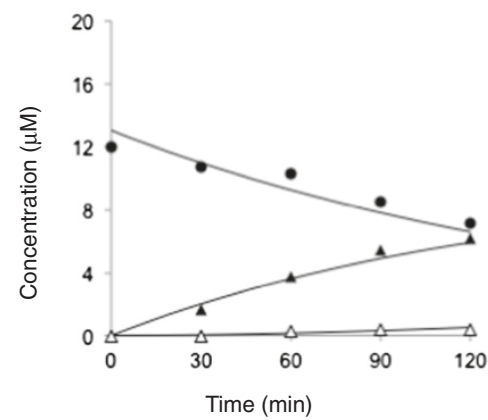

(g) M1-6 ( $\left.\operatorname{LinB}_{U T} \mathrm{~A} 247 \mathrm{H}\right)$

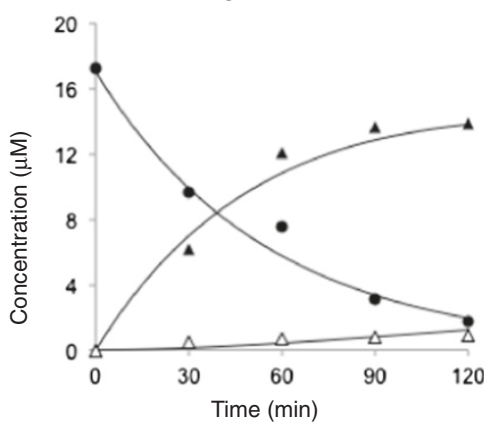

(j) $\mathrm{M} 3-1(\mathrm{M} 2-1+\mathrm{A} 112 \mathrm{~V})$

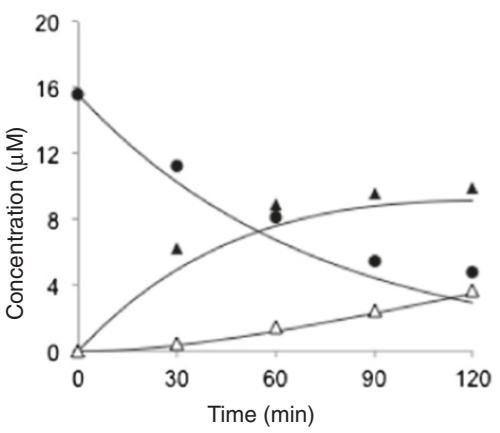

(e) M1-4 ( LinB $_{U T}$ A135T)

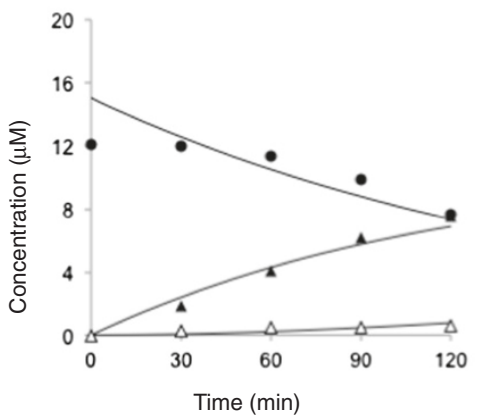

(h) M1-7 (LinB ${ }_{U T}$ M253I)

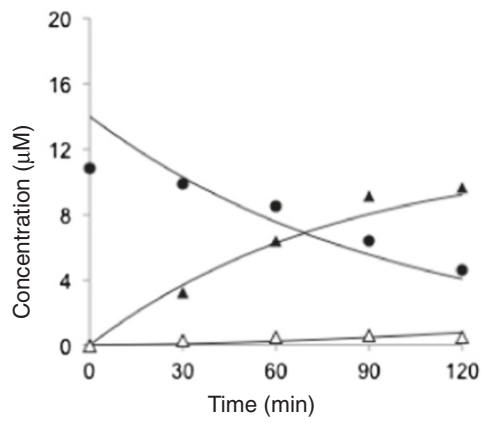

(k) M3-2 (M2-1 + I138L)

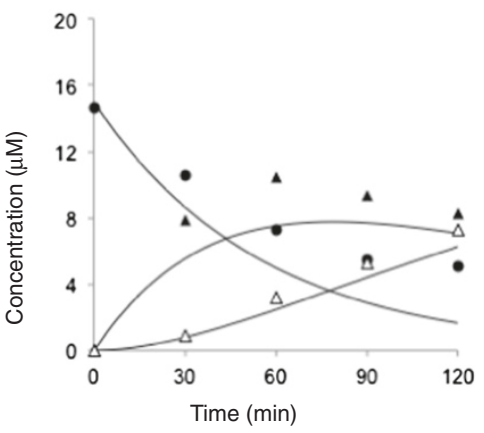

(c) M1-2 (LinB ${ }_{U T}$ A112V)

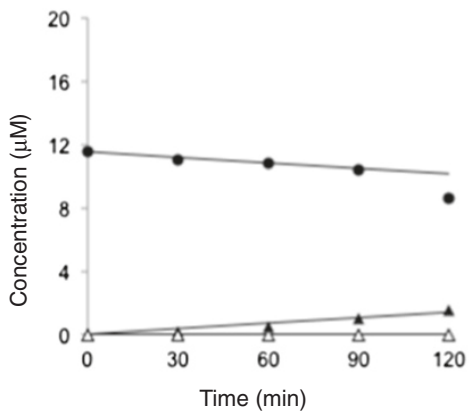

(f) $\mathrm{M} 1-5\left(\mathrm{LinB}_{\mathrm{UT}}\right.$ I138L)

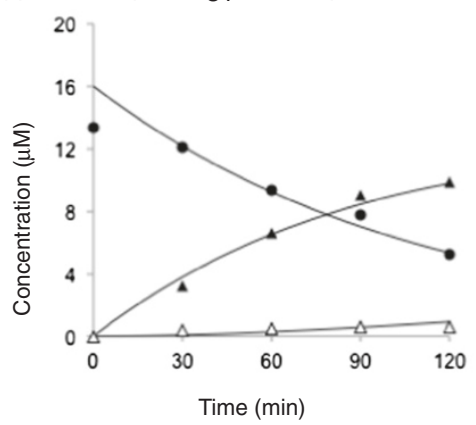

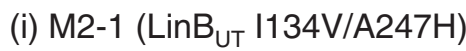

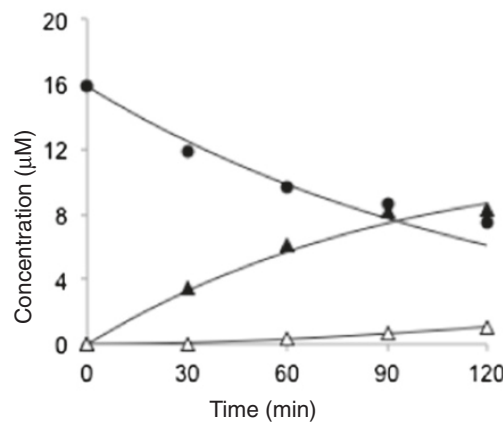

(I) M3-3 (M2-1 + M253I)

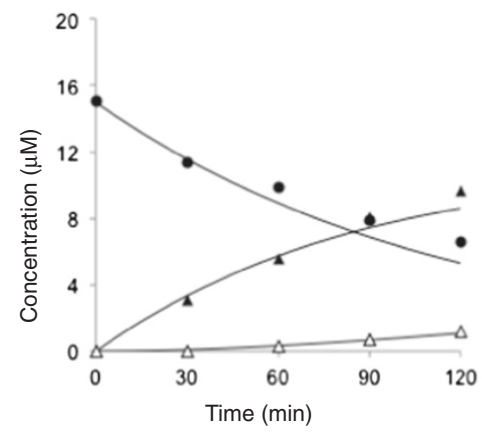

Figure 3 (See legend on next page.) 
(See figure on previous page.)

Figure 3 Degradation of $\beta-\mathrm{HCH}$ in reaction mixtures containing LinB $\mathrm{BT}_{U \mathrm{~T}}$ and its mutant derivatives. LinB $\mathrm{BT}_{\mathrm{T}}$ wild-type (a) and its mutants, M1-1 (b), M1-2 (c), M1-3 (d), M1-4 (e), M1-5 (f), M1-6 (g), M1-7 (h), M2-1 (i), M3-1 (j), M3-2 (k), M3-3 (l). The closed circle and closed and open triangles represent $\beta-H C H, P C H L$, and TCDL, respectively. Each value given is the mean of triplicates. Kinetic data were fitted to the irreversible two-step reaction scheme of $\beta$-HCH conversion to TCDL via PCHL (Scheme 1 in Materials and methods) by using GEPASI 3.2 software (Mendes 1997) and shown in solid lines. The specificity constants and their standard errors for both reaction steps $\left(k_{1}\right.$ and $\left.k_{2}\right)$ were obtained from the calculation (Table 1).

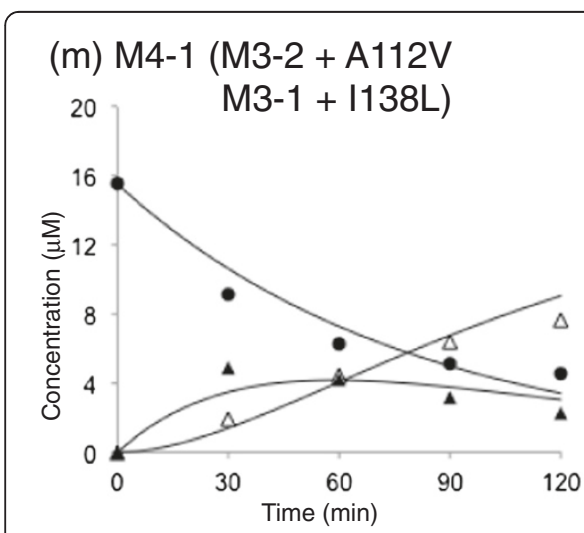

(p) M5-2 (M4-2 + A81T)

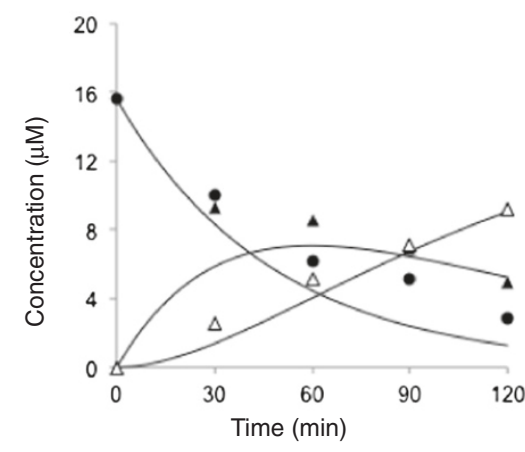

(s) M5-5 (M4-1 + A135T)

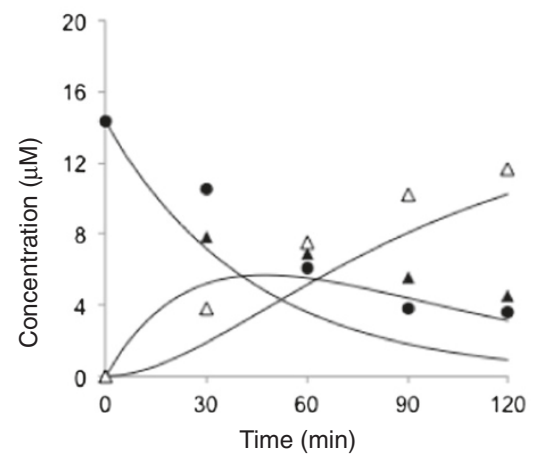

(n) M4-2 (M3-2 + M253I

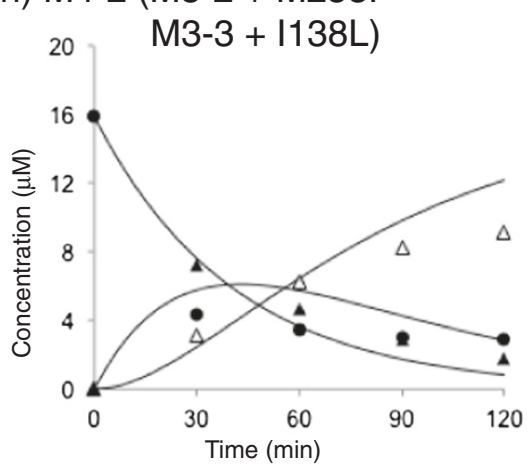

(q) $\mathrm{M} 5-3(\mathrm{M} 4-2+\mathrm{A} 135 \mathrm{~T})$

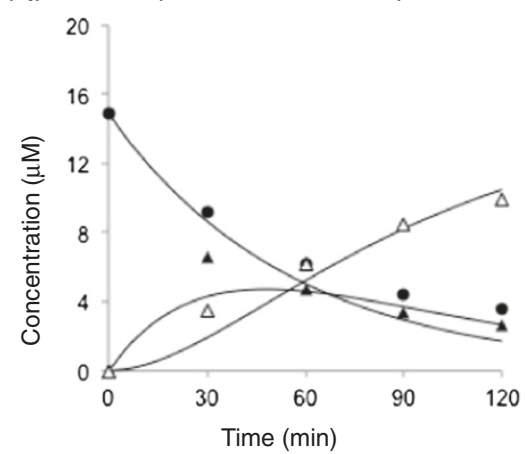

(o) M5-1 (M4-2 + A112V

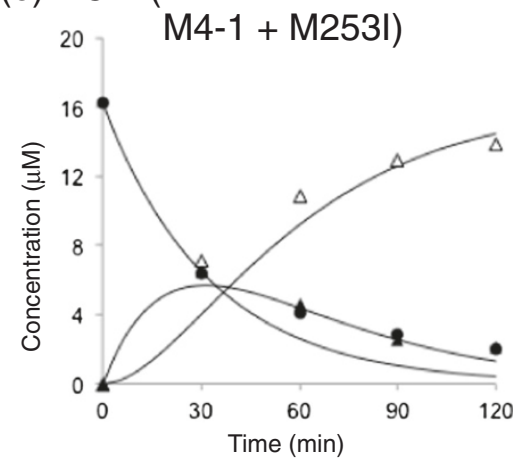

(r) $\mathrm{M} 5-4(\mathrm{M} 4-1+\mathrm{A} 81 \mathrm{~T})$

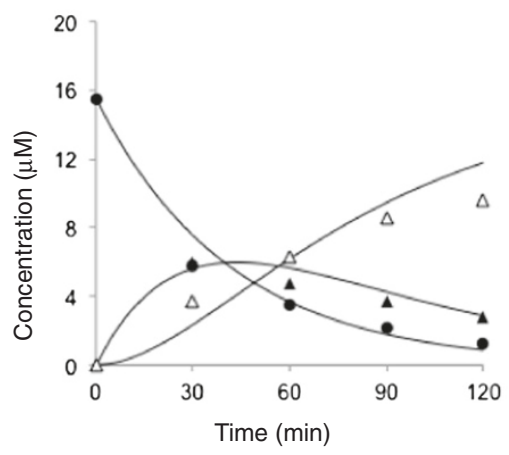

Figure 4 Degradation of $\beta-H C H$ in reaction mixtures containing $\operatorname{LinB}_{U T}$ mutant derivatives. M4-1 (m), M4-2 (n), M5-1 (o), M5-2 (p), M5-3 (q), M5-4 (r), and M5-5 (s). See legend of Figure 3. 
Table 1 Specificity constants of LinB ${ }_{U T}, \operatorname{LinB}_{M l}$, and their intermediate mutants

\begin{tabular}{|c|c|c|c|c|c|c|c|c|c|c|c|c|c|c|}
\hline \multicolumn{3}{|c|}{ Enzyme } & \multicolumn{7}{|c|}{ Position of the different amino acid residues } & \multicolumn{4}{|c|}{ Specificity constant $k_{\text {cat }} / K_{\mathrm{m}}\left(\mathrm{M}^{-1} \mathrm{~s}^{-1}\right)$} & \multirow[t]{2}{*}{ Data source } \\
\hline Fold $^{a}$ & Mutant name & & 81 & 112 & 134 & 135 & 138 & 247 & 253 & $\mathrm{HCH} \rightarrow \mathrm{PCHL}$ & $\%$ to $\operatorname{Lin} B_{M I}$ & $\mathrm{PCHL} \rightarrow \mathrm{TCDL}$ & $\%$ to $\operatorname{Lin} B_{M I}$ & \\
\hline 0 & $\operatorname{LinB}_{U T}$ & & A & A & I & A & I & A & M & $17 \pm 0$ & 9 & $2.0 \pm 1$ & 0.2 & This study ${ }^{b}$ \\
\hline 1 & $\mathrm{LinB}_{\mathrm{UT}} \mathrm{A} 81 \mathrm{~T}$ & M1-1 & T & A & । & A & । & A & M & $92 \pm 3$ & 50 & $2.0 \pm 1$ & 0.2 & This study \\
\hline 1 & LinB $\mathrm{BT}_{\mathrm{T}} \mathrm{A} 112 \mathrm{~V}$ & M1-2 & A & V & I & A & I & A & M & $4 \pm 0$ & 2.1 & 0 & 0 & This study \\
\hline 1 & LinBut I134V & M1-3 & A & A & V & A & । & A & M & $21 \pm 0$ & 11 & $5 \pm 1$ & 0.5 & This study ${ }^{b}$ \\
\hline 1 & $\mathrm{LinB}_{U T} \mathrm{~A} 135 \mathrm{~T}$ & M1-4 & A & A & । & $\mathrm{T}$ & I & A & M & $23 \pm 1$ & 12 & $6 \pm 2$ & 0.6 & This study \\
\hline 1 & LinBut 1138L & M1-5 & A & A & 1 & A & L & A & M & $35 \pm 1$ & 18 & $5 \pm 1$ & 0.5 & This study \\
\hline 1 & LinBut A247H & M1-6 & A & A & 1 & A & 1 & H & M & $68 \pm 2$ & 36 & $4 \pm 1$ & 0.4 & This study ${ }^{b}$ \\
\hline 1 & LinBut M2531 & $\mathrm{M} 1-7$ & A & A & 1 & A & । & A & 1 & $39 \pm 1$ & 21 & $4 \pm 1$ & 0.4 & This study \\
\hline 2 & $\mathrm{LinB}_{\mathrm{UT}}$ I134V/A247H & M2-1 & A & A & V & A & । & $\mathrm{H}$ & M & $30 \pm 0$ & 16 & $7 \pm 1$ & 0.7 & This study ${ }^{b}$ \\
\hline 3 & 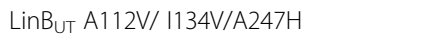 & M3-1 & A & V & V & A & । & $\mathrm{H}$ & M & $53 \pm 3$ & 28 & $17 \pm 2$ & 1.7 & This study \\
\hline 3 & LinBut I134V/1138L/A247H & M3-2 & A & A & V & A & L & $\mathrm{H}$ & M & $69 \pm 10$ & 36 & $31 \pm 7$ & 3.1 & This study \\
\hline 3 & LinB ${ }_{\text {UT }}$ I134V/A247H/M253I & M3-3 & A & A & V & A & । & $\mathrm{H}$ & । & $33 \pm 1$ & 17 & $7 \pm 1$ & 0.7 & This study \\
\hline 4 & LinBut A112V//134V/1138L/A247H & M4-1 & A & V & V & A & L & $\mathrm{H}$ & M & $48 \pm 4$ & 25 & $85 \pm 10$ & 8.5 & This study \\
\hline 4 & $\mathrm{LinB}_{U \mathrm{UT}}$ I134V/1138L/A247H/M253I & $M 4-2$ & A & A & v & A & L & $\mathrm{H}$ & । & $1.0 \pm 0.2 \times 10^{2}$ & 53 & $83 \pm 20$ & 8.3 & This study \\
\hline 5 & LinB UT A112V/1134V/1138L/A247H/M2531 & M5-1 & A & v & v & A & L & $\mathrm{H}$ & 1 & $1.2 \pm 0.1 \times 10^{2}$ & 63 & $1.3 \pm 0.2 \times 10^{2}$ & 13 & This study \\
\hline 5 & LinB UT A81T/I134V/1138L/A247H/M253I & M5-2 & T & A & V & A & L & H & । & $79 \pm 10$ & 42 & $50 \pm 10$ & 5 & This study \\
\hline 5 & LinBut 1134V/A135T//138L/A247H/M253I & M5-3 & A & A & V & $\mathrm{T}$ & L & $\mathrm{H}$ & 1 & $68 \pm 8$ & 36 & $90 \pm 20$ & 9 & This study \\
\hline 5 & LinB ${ }_{\text {UT }}$ A81T/A112V/1134V/1138L/A247H & M5-4 & T & V & V & A & L & $\mathrm{H}$ & M & $91 \pm 9$ & 48 & $83 \pm 10$ & 8.3 & This study \\
\hline 5 & LinB ${ }_{\text {UT }} \mathrm{A} 112 \mathrm{~V} / 1134 \mathrm{~V} / \mathrm{A} 135 \mathrm{~T} / \mathrm{I138L/A247H}$ & M5-5 & A & V & V & $\mathrm{T}$ & L & $\mathrm{H}$ & M & $84 \pm 20$ & 44 & $73 \pm 20$ & 7.3 & This study \\
\hline 6 & $\operatorname{LinB}_{M I}$ T81A & M6-1 & A & v & V & $T$ & L & H & । & $68 \pm 3$ & 36 & $9.5 \pm 5.0 \times 10^{2}$ & 95 & Okai et al. 2013 \\
\hline 6 & $\operatorname{LinB}_{\mathrm{MI}} \mathrm{V} 112 \mathrm{~A}$ & M6-2 & $T$ & A & V & $T$ & L & H & । & $1.0 \pm 0.09 \times 10^{2}$ & 53 & $2.3 \pm 0.4 \times 10^{2}$ & 23 & Okai et al. 2013 \\
\hline 6 & $\operatorname{LinB}_{M I} V 1341$ & M6-3 & $T$ & v & । & $T$ & L & H & । & $1.2 \pm 0.05 \times 10^{2}$ & 63 & $80 \pm 3$ & 8 & Ito et al. 2007 \\
\hline 6 & $\operatorname{LinB}_{\mathrm{MI}} \mathrm{T} 135 \mathrm{~A}$ & $M 6-4$ & $T$ & v & V & A & L & H & I & $83 \pm 5$ & 44 & $4.2 \pm 1 \times 10^{2}$ & 42 & Okai et al. 2013 \\
\hline 6 & $\operatorname{LinB}_{M I} \operatorname{L} 1381$ & M6-5 & $\mathrm{T}$ & V & V & $\mathrm{T}$ & । & H & I & $1.3 \pm 0.1 \times 10^{2}$ & 68 & $2.2 \pm 0.4 \times 10^{2}$ & 22 & Okai et al. 2013 \\
\hline 6 & $\operatorname{LinB}_{M I} \mathrm{H} 247 \mathrm{~A}$ & M6-6 & $T$ & V & V & $T$ & L & A & 1 & $2.1 \pm 0.2 \times 10^{2}$ & 111 & $2.4 \pm 0.2 \times 10^{2}$ & 24 & Ito et al. 2007 \\
\hline 6 & $\operatorname{LinB}_{M I} 1253 \mathrm{M}$ & M6-7 & $\mathrm{T}$ & V & V & $\mathrm{T}$ & L & $\mathrm{H}$ & M & $2.1 \pm 0.3 \times 10^{2}$ & 111 & $1.4 \pm 0.2 \times 10^{2}$ & 14 & Okai et al. 2013 \\
\hline 7 & $\operatorname{LinB}_{M I}$ & & $T$ & v & V & $T$ & L & H & । & $1.9 \pm 0.08 \times 10^{2}$ & 100 & $1.0 \pm 0.3 \times 10^{3}$ & 100 & Okai et al. 2013 \\
\hline
\end{tabular}


(a) total

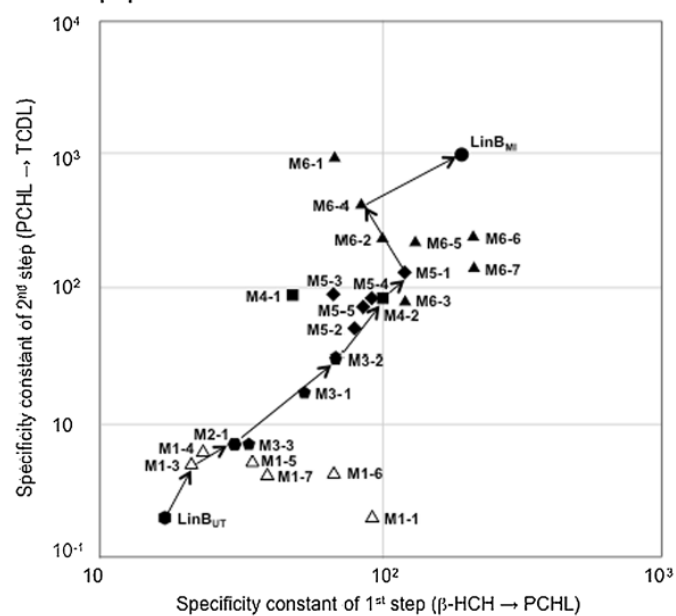

(c) I138L mutation

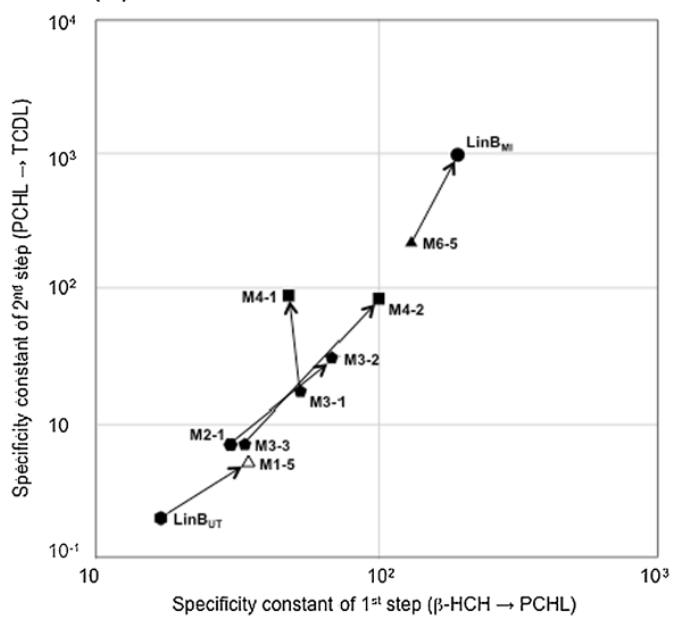

(e) A81T mutation

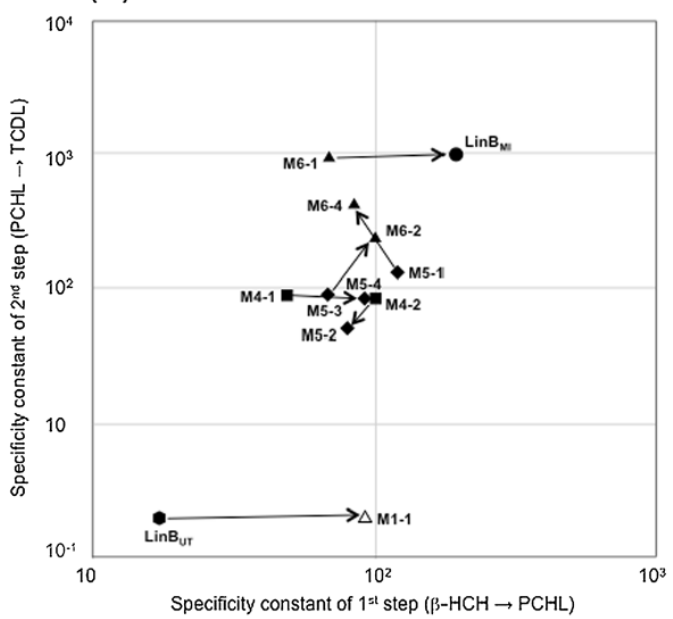

Figure 5 (See legend on next page.) (b) A112V mutation

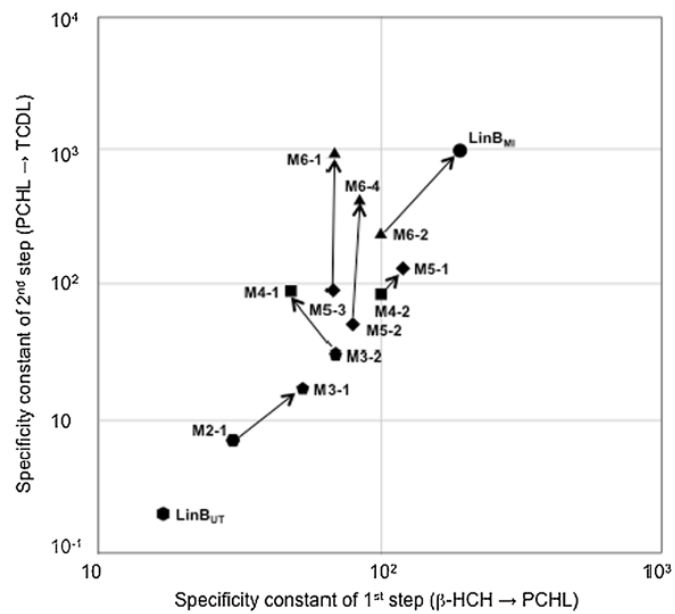

(d) M253I mutation

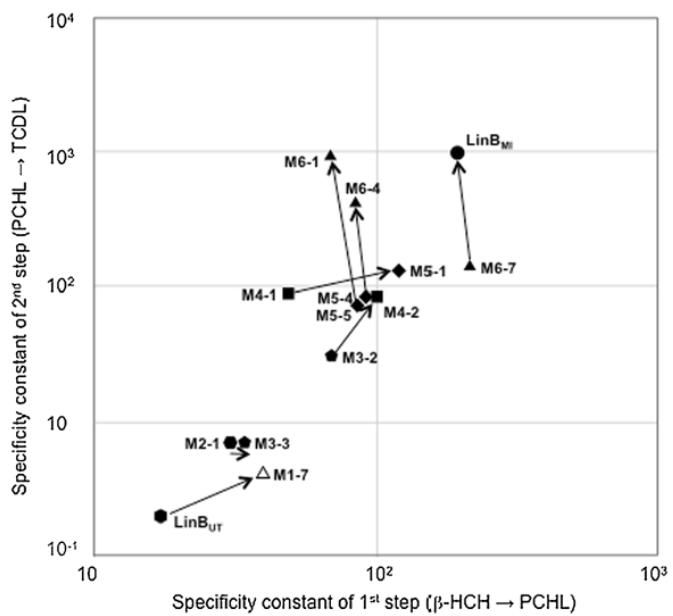

(f) A135T mutation

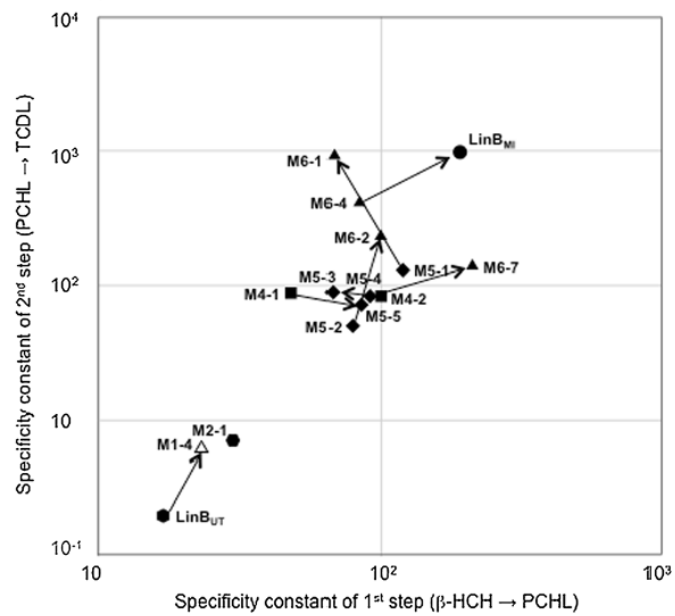




\section{Characterization of three-point mutants of LinB}

The importance of V112, L138, and I253 for $\mathrm{LinB}_{\mathrm{MI}}$-type activity was suggested in a previous study (Okai et al. 2013). Therefore, the A112V, I138L, and M253I mutations were independently introduced into $\mathrm{M} 2-1$, resulting in three-point mutants: M3-1 (Figure 3j), M3-2 (Figure 3k), and M3-3 (Figure 31), respectively. These three mutations showed different effects on $\beta-\mathrm{HCH}$ degradation activity (Figure 5a and Table 1). The I138L mutation positively influenced both conversion steps (Figure 5c: M2-1 to M3-2), while the M253I mutation had only a weak positive effect on the first conversion step (Figure $5 \mathrm{~d}$ : M2-1 to M3-3). The A112V mutation showed positive effects on both conversion steps (Figure 5b: M2-1 to M3-1), although the effects were lower than those of I138L (Figure 5a).

\section{Characterization of four-point mutants of LinB $\mathrm{BT}_{\mathrm{UT}}$}

Since M3-2 showed the highest $\beta-\mathrm{HCH}$ degradation activity among the evaluated three-point mutants (Figure 5a and Table 1), the A112V and M253I mutations were independently introduced into M3-2, giving rise to four-point mutants, M4-1 (Figure 4m) and M4-2 (Figure $4 n$ ), respectively. These mutations resulted in similar levels of positive effects on the second conversion step, but the M253I (M3-2 to M4-2) and A112V (M3-2 to M4-1) mutations had positive and negative effects, respectively, on the rates of the first conversion step (Figure 5a, b, d and Table 1). M4-1 and M4-2 are equivalent to the I138L mutants of M3-1 and M3-3, respectively. Therefore, the $1138 \mathrm{~L}$ mutation had a relatively high level of positive effects on the second conversion step in the cases of M3-1 to M4-1 and M3-3 to M4-2, and also had a positive effect on the first conversion step in the latter case (Figure $5 \mathrm{c}$ and Table 1 ).

\section{Characterization of five-point mutants of LinB $\mathrm{BT}_{\mathrm{UT}}$}

We further constructed a five-point mutant of LinB $_{\mathrm{UT}}$ (A112V/I134V/I138L/A247H/M253I: M5-1) (Figure 4o), which has the mutations at all five amino acid residues that were suggested to be important for $\beta-\mathrm{HCH}$ degradation activity. This mutant can be constructed by the introduction of M253I and A112V mutations into M4-1 and M4-2, respectively. The enzymatic activities of M5-1 indeed increased in both conversion steps compared with those by the parental M4-1 and M4-2 mutants (Figure 5a and Table 1).
All of the other four possible five-point mutants from M4-2 or M4-1 were also constructed: M5-2 (Figure 4p) and M5-3 (Figure 4q) from M4-2, and M5-4 (Figure 4r) and M5-5 (Figure 4s) from M4-1. None of them surpassed the activity of M5-1 (Figure $5 \mathrm{a}$ ). The rates of both conversion steps using M5-2 and M5-3 decreased or remained at levels similar to those of the M4-2 mutant (Figure 5a). On the other hand, the rates of the first conversion step by M5-4 and M5-5 were higher than that by the parental enzyme, M4-1, but the rates of the second conversion step of these mutants remained indistinguishable from that of M4-1 (Figure 5a).

\section{Discussion}

In this study, cumulative substitution mutations were introduced into $\mathrm{LinB}_{\mathrm{UT}}$, and various intermediate mutant enzymes between $\operatorname{LinB}_{\mathrm{UT}}$ and $\operatorname{LinB}_{\mathrm{MI}}$ were kinetically characterized (Figures 3, 4 and Table 1). Since LinB has promiscuous enzymatic activities towards various compounds, including other $\mathrm{HCH}$ isomers and various haloalkanes (Lal et al. 2010), the functional evolution of LinB seems too complicated to analyze. However, we focused in this study on its $\beta-\mathrm{HCH}$ degradation activity as a representative model. Overall, the $\beta-\mathrm{HCH}$ degradation activities of the mutants gradually changed to those of a $\mathrm{LinB}_{\mathrm{MI}}$-type enzyme according to the number of introduced mutations (Figure 5a), indicating that the function of $\operatorname{LinB}$ towards this activity can evolve in a stepwise manner. However, the effects of the particular amino acid substitutions depended on the order of the introduced mutations or on the combination with other mutations, and every substitution influenced both the first and second conversion steps (Figure 5b-f). Especially, the I138L mutation showed relatively strong positive effects on both conversion steps in almost all mutant enzymes examined (Figure 5c), suggesting this mutation plays a key role in $\mathrm{LinB}_{\mathrm{MI}}$-type activity. At the beginning of this study, we mainly focused on three mutations, A112V, I138L, and M253I, on the basis of the results of our previous mutational and structural analyses of $\operatorname{LinB}_{\mathrm{MI}}$ (Okai et al. 2013), but our additional analysis in this study also confirmed the involvement of A81T and A135T mutations in $\beta-\mathrm{HCH}$ degradation activity (Figure $5 \mathrm{e}, \mathrm{f}$ ). It is of interest that the T81 residue of $\operatorname{Lin}_{\mathrm{MI}}$ was mainly involved in the first conversion step (Figure 5e). However, it is at present unclear how this residue contributed so substantially to such 
a step, because T81 is located on the protein surface and far away from the active site and access tunnels (Figure 2) (Okai et al. 2013).

Two examples of plausible evolutionary routes of different protein functions between two highly similar proteins have recently been reported. One example is the route to the formation of atrazine chlorohydrolase (AtzA) and melamine deaminase (TriA) (Noor et al. 2012), which are 98\% identical (nine amino acid differences in the 475 amino acid proteins). AtzA catalyzes the dehalogenation of halo-substituted triazine ring compounds but shows no activity towards melamine or ammeline (Seffernick et al. 2001), whereas TriA has no detectable activity toward the halo-triazine substrates (Seffernick et al. 2001). The nine amino acid substitutions for generating the different enzymatic activities could have occurred in either enzyme (Noor et al. 2012). The other example is the route of the evolution of NtdR (a regulator of the nitrotoluene degradation pathway) from NagR (a regulator of the naphthalene degradation pathway) (Ju et al. 2009). Although these two regulators are 98\% identical (five differences among 301 amino acids), NtdR, but not NagR, can recognize a wide spectrum of nitroaromatic compounds. It has been proposed that NtdR evolved from NagR by stepwise broadening of the effector range without loss of the original function (Ju et al. 2009). We also demonstrated in this study that $\operatorname{LinB}_{\mathrm{UT}}$ could be changed to $\operatorname{LinB}_{\mathrm{MI}}$ by the accumulation of seven point mutations, and that the plausible evolutionary routes could be predicted. For example, if the $\beta-\mathrm{HCH}$ degradation activity of $\mathrm{LinB}_{\mathrm{UT}}$ increased under relevant selection pressure, the following order of mutations would be most likely: I134V ( LinB $_{\mathrm{UT}}$ to M1-3) - A247H (M1-3 to M2-1) - I138L (M2-1 to M3-2) M253I (M3-2 to M4-2) - A112V (M4-2 to M5-1) - A81T (M5-1 to M6-4) - A135T (M6-4 to LinB ${ }_{M I}$ ) (Figure 5a). In this order, the activity for the second conversion increases gradually by every mutation step. Although the activity for the first conversion decreases at the 6th step, the second conversion seems to be more important for the $\mathrm{LinB}_{\mathrm{MI}^{-}}$ type activity, since $\operatorname{Lin}_{\mathrm{UT}}$ has nearly no activity for the second conversion.

However, we have to keep in mind that it is impossible at present to predict the diverging processes of $\operatorname{LinB}_{\mathrm{MI}}$ and LinB $_{U T}$ in the environment, since (i) we have not constructed all possible intermediate mutants between LinB $_{M I}$ and LinB $_{U T}$, and (ii) their common ancestral enzyme remains unknown. All eight nucleotide substitutions (in the seven codons) between $\operatorname{lin} B_{\mathrm{MI}}$ and $\operatorname{lin} B_{\mathrm{UT}}$ are nonsynonymous (Ito et al. 2007), suggesting that $\operatorname{LinB}_{M I}$ and $\operatorname{Lin}_{\mathrm{UT}}$ diverged relatively recently from a common ancestral LinB protein under strong selection pressure. However, the benefit of the $\mathrm{LinB}_{\mathrm{MI}}$-type activity to the host cells is still unknown. TCDL is a dead-end product in strain MI1205 (Ito et al. 2007), indicating the inability of this strain to use $\beta-\mathrm{HCH}$ as a carbon and energy source. Furthermore, TCDL seems to be more toxic than $\beta-\mathrm{HCH}$, because a UT26 derivative whose $\operatorname{lin} B_{\mathrm{UT}}$ gene is replaced by $\operatorname{lin} B_{\mathrm{MI}}$ showed a growth defect in the presence of $\beta-\mathrm{HCH}$ (unpublished data). In other words, the $\beta-\mathrm{HCH}$ degradation activity itself is apparently unfavorable even for the host cells in the presence of $\beta-\mathrm{HCH}$. $\beta-\mathrm{HCH}$ degradation activity may be beneficial when cells with this activity coexist with other types of cells having enzymes for the metabolism of TCDL. In the $\gamma$-HCH metabolism, LinB converts 1,3,4,6-tetrachloro-1,4-cyclohexadiene, which is produced from $\gamma-\mathrm{HCH}$ by LinA (Nagata et al. 1993). Our preliminary analysis indicated that there was no difference between the $\mathrm{LinB}_{\mathrm{UT}^{-}}$and $\mathrm{LinB}_{\mathrm{MI}}$-catalyzed transformation activities towards the intermediate (unpublished data). It has been proposed that enzymatic promiscuity is important for protein evolution (Aharoni et al. 2005; Khersonsky et al. 2006), and $\operatorname{Lin}_{\mathrm{MI}}$ may be in a more promiscuous state than $\operatorname{Lin}_{\mathrm{UT}}$. More detailed studies are needed to elucidate the physiological significance of the activity unique to $\operatorname{LinB}_{\mathrm{MI}}$.

All seven dissimilar amino acid residues are involved in the $\beta-\mathrm{HCH}$ degradation activity unique to $\mathrm{LinB}_{\mathrm{MI}}$, and their positions in the structure of $\operatorname{LinB}_{\mathrm{MI}}$ can partially explain their functions in this activity, as described above (Figure 2) (Okai et al. 2013). However, the detailed mechanism by which they contribute to the catalytic activity is not fully understood, because the effect of each successive amino acid substitution depends on the combination of other mutations. Furthermore, all seven mutations showed substantial positive effects at the final stage of their introduction (six-point mutants of LinB $\mathrm{Bu}_{\mathrm{UT}}$, Figure $5 \mathrm{a}$ ). These results suggested that the synergetic effects are important for the activity. Numerous naturally occurring LinB variants have recently been reported (Additional file 1: Table S1). Although the seven amino acid residues described herein indeed seem to be the hot spots for mutations in the variants, variations in other amino acid residues, such as 134L, 247S, and 253L, were also found (Additional file 1: Table S1). To discuss the evolution of LinB critically, the effects of such novel substitutions on the $\beta-\mathrm{HCH}$ degradation activity should be addressed in future studies. Furthermore, this study also describes the influence of several mutations on the enzymatic activity of LinB and helps in understanding the structure-function relationship. This information might be useful in future for rational design of LinBs with improved activity.

\section{Additional file}

Additional file 1: Figure S1. Degradation of $\beta-\mathrm{HCH}$ (closed circle) and appearance of its metabolites, PCHL (closed triangle) and TCDL (open triangle), in reaction mixtures containing $\operatorname{LinB}_{\mathrm{Ml}}$ wild-type (a), and seven 
point mutants of $L_{i n} B_{M I}(b-h)$. Values given are the mean of triplicates. Kinetic data were fitted to the irreversible two-step reaction structure of $\beta-H C H$ conversion to TCDL via PCHL (Scheme 1 in Materials and Methods) by using GEPASI 3.2 software (Mendes 1997) and shown in solid lines. The specificity constants and their standard errors for both reaction steps $\left(k_{1}\right.$ and $k_{2}$ ) were obtained from the calculation (Table 1 ). The same data were used that have already been published by lto et al (2007) (panels d and g) and Okai et al (2013) (panels a, b, c, e, f, and h). Table S1. Naturally occurring LinB variants.

\section{Competing interests}

The authors declared that they have no competing interests.

\section{Authors' contributions}

RM, HT, YNit, Mlsh, and Mlto designed and performed experiments. YO participated in the design of the study. JD and ZP analyzed data. MT, JD, ZP, and YNag participated in the design and coordination of this study and drafted the manuscript. YNag conceived the study and is the responsible of the entire project. All authors read and approved the final manuscript.

\section{Acknowledgements}

This work was supported by Grant-in-Aids for Scientific Research from Ministry of Education, Culture, Sports, Science, and Technology, and Ministry of Agriculture, Forestry, and Fisheries of Japan, the Grant Agency of the Czech Republic (P503/12/0572) and the Czech Ministry of Education (LO1214).

\section{Author details}

'Department of Environmental Life Sciences, Graduate School of Life Sciences, Tohoku University, Sendai 980-8577, Japan. ${ }^{2}$ Loschmidt Laboratories, Department of Experimental Biology and Research Centre for Toxic Compounds in the Environment RECETOX, Faculty of Science, Masaryk University, Kamenice 5/A13, 62500 Brno, Czech Republic. ${ }^{3}$ The United Graduate School of Agricultural Science, Gifu University 1-1 Yanagido, Gifu 501-1193, Japan. ${ }^{4}$ Consolidated Research Institute for Advanced Science and Medical Care, Waseda University, 2-2 Wakamatsu-cho, Shinjuku, Tokyo 162-8480, Japan

Received: 11 July 2014 Accepted: 18 August 2014

Published online: 21 September 2014

\section{References}

Aharoni A, Gaidukov L, Khersonsky O, Mc QGS, Roodveldt C, Tawfik DS (2005) The 'evolvability' of promiscuous protein functions. Nature Genet 37:73-76

Damborsky J, Koca J (1999) Analysis of the reaction mechanism and substrate specificity of haloalkane dehalogenases by sequential and structural comparisons. Protein Eng 12:989-998

Gupta A, Kaushik C, Kaushik A (2000) Degradation of hexachlorocyclohexane ( $\mathrm{HCH} ; \alpha, \beta, \gamma$ and $\delta$ ) by Bacillus circulans and Bacillus brevis isolated from soil contaminated with HCH. Soil Biol Biochem 32:1803-1805

Gupta A, Kaushik CP, Kaushik A (2001) Degradation of hexachlorocyclohexane isomers by two strains of Alcaligenes faecalis isolated from a contaminated site. Bull Environ Contam Toxicol 66:794-800

Ito M, Prokop Z, Klvana M, Otsubo Y, Tsuda M, Damborsky J, Nagata Y (2007) Degradation of $\beta$-hexachlorocyclohexane by haloalkane dehalogenase LinB from $\gamma$-hexachlorocyclohexane-utilizing bacterium Sphingobium sp. Ml1205. Arch Microbiol 188:313-325

Janssen DB (2004) Evolving haloalkane dehalogenases. Curr Opin Chem Biol 8:150-159

Johri A, Dua M, Tuteja D, Saxena R, Saxena D, Lal R (1998) Degradation of a, $\beta$, $\gamma$ and $\delta$-hexachlorocyclohexanes by Sphingomonas paucimobilis. Biotechnol Lett 20:885-887

Ju KS, Parales JV, Parales RE (2009) Reconstructing the evolutionary history of nitrotoluene detection in the transcriptional regulator NtdR. Mol Microbiol 74:826-843

Khersonsky O, Roodveldt C, Tawfik DS (2006) Enzyme promiscuity: evolutionary and mechanistic aspects. Curr Opin Chem Biol 10:498-508

Lal R, Dogra C, Malhotra S, Sharma P, Pal R (2006) Diversity, distribution and divergence of lin genes in hexachlorocyclohexane-degrading sphingomonads. Trends Biotechnol 24:121-130
Lal R, Pandey G, Sharma P, Kumari K, Malhotra S, Pandey R, Raina V, Kohler HP, Holliger C, Jackson C, Oakeshott JG (2010) Biochemistry of microbial degradation of hexachlorocyclohexane and prospects for bioremediation. Microbiol Mol Biol Rev 74:58-80

Mendes P (1997) Biochemistry by numbers: simulation of biochemical pathways with Gepasi 3. Trends Biochem Sci 22:361-363

Mohn WW, Mertens B, Neufeld JD, Verstraete W, de Lorenzo V (2006) Distribution and phylogeny of hexachlorocyclohexane-degrading bacteria in soils from Spain. Environ Microbiol 8:60-68

Nagata Y, Nariya T, Ohtomo R, Fukuda M, Yano K, Takagi M (1993) Cloning and sequencing of a dehalogenase gene encoding an enzyme with hydrolase activity involved in the degradation of $y$-hexachlorocyclohexane in Pseudomonas paucimobilis. J Bacteriol 175:6403-6410

Nagata Y, Prokop Z, Sato Y, Jerabek P, Kumar A, Ohtsubo Y, Tsuda M, Damborsky J (2005) Degradation of $\beta$-hxachlorocyclohexane by haloalkane dehalogenase LinB from Sphingomonas paucimobilis UT26. Appl Environ Microbiol 71:2183-2185

Noor S, Taylor MC, Russell RJ, Jermiin LS, Jackson CJ, Oakeshott JG, Scott C (2012) Intramolecular epistasis and the evolution of a new enzymatic function. PLoS One 7(6):e39822

Okai M, Ohtsuka J, Imai LF, Mase T, Moriuchi R, Tsuda M, Nagata K, Nagata Y, Tanokura M (2013) Crystal structure and site-directed mutagenesis analyses of haloalkane dehalogenase LinB from Sphingobium sp. MI1205. J Bacteriol 195:2642-2651

Phillips TM, Seech AG, Lee H, Trevors JT (2005) Biodegradation of hexachlorocyclohexane $(\mathrm{HCH})$ by microorganisms. Biodegradation 16:363-392

Prokop Z, Monincova M, Chaloupkova R, Klvana M, Nagata Y, Janssen DB, Damborsky J (2003) Catalytic mechanism of the haloalkane dehalogenase LinB from Sphingomonas paucimobilis UT26. J Biol Chem 278:45094-45100

Seffernick JL, de Souza ML, Sadowsky MJ, Wackett LP (2001) Melamine deaminase and atrazine chlorohydrolase: 98 percent identical but functionally different. J Bacteriol 183:2405-2410

Sharma P, Raina V, Kumari R, Malhotra S, Dogra C, Kumari H, Kohler HP, Buser HR, Holliger C, Lal R (2006) Haloalkane dehalogenase LinB is responsible for $\beta$ - and $\delta$-hexachlorocyclohexane transformation in Sphingobium indicum B90A. Appl Environ Microbiol 72:5720-5727

Vijgen J, Abhilash PC, Li YF, Lal R, Forter M, Torres J, Singh N, Yunus M, Tian C, Schaffer A, Weber R (2011) Hexachlorocyclohexane (HCH) as new Stockholm Convention POPs-a global perspective on the management of Lindane and its waste isomers. Environ Sci Pollut Res Int 18:152-162

Willett KL, Ulrich EM, Hites RA (1998) Differential toxicity and environmental fates of hexachlorocyclohexane isomers. Environ Sci Technol 32:2197-2207

\section{doi:10.1186/s13568-014-0072-5}

Cite this article as: Moriuchi et al:: Stepwise enhancement of catalytic performance of haloalkane dehalogenase LinB towards $\beta$-hexachlorocyclohexane. AMB Express 2014 4:72.

\section{Submit your manuscript to a SpringerOpen ${ }^{\odot}$ journal and benefit from:}

- Convenient online submission

$\checkmark$ Rigorous peer review

- Immediate publication on acceptance

- Open access: articles freely available online

- High visibility within the field

- Retaining the copyright to your article

Submit your next manuscript at $\boldsymbol{\wedge}$ springeropen.com 